\title{
Perspectivas de atuação como docente e em foro civil para o especialista em Odontologia Legal
}

\author{
Fábio Elpídio Silva*; Wellington Menyrval Zaitter**; Mário Marques Fernandes*** \\ * Cirurgião-Dentista Especializando em Odontologia Legal pela \\ Universidade Positivo, Curitiba/PR \\ ** Especialista, Mestre e Doutor em Odontologia Legal pela FOUSP, \\ Professor Titular e Coordenador do Curso de Especialização em \\ Odontologia Legal da Universidade Positivo, Curitiba/PR \\ *** Doutor em Odontologia Legal pela FOUSP, Professor \\ Coordenador do Curso de Especialização em Odontologia Legal \\ da ABORS, Porto Alegre/RS
}

Recebido em 27/10/2016. Aprovado em 24/11/2016.

\begin{abstract}
RESUMO
A Odontologia Legal se relaciona com todas as demais especialidades odontológicas, fazendo a ligação entre a Odontologia e o Direito. Dentre as diversas possibilidades de atuação, se encontram a docência, bem como as perícias nos diferentes foros, e nesse contexto, as existentes em âmbito cível, nas quais o especialista é nomeado para conduzir o trabalho pericial em demandas que envolvem muitas vezes a responsabilidade profissional. O presente trabalho tem como objetivo correlacionar dados disponíveis sobre inscritos nas especialidades odontológicas, cursos de especialização existentes, e Faculdades de Odontologia registradas no Brasil, destacando a perspectiva de atuação do especialista em Odontologia Legal em docência e na prática pericial civil. Trata-se de uma pesquisa quantitativa, descritiva e bibliográfica, com levantamento percentual e numérico, para análise da distribuição geográfica de especialistas em Odontologia Legal e comparação com os especialistas em implantodontia e ortodontia, atualmente as especialidades com maior demanda em processos judiciais no Brasil. Paralelamente foi realizado um levantamento numérico dos cursos de graduação e pós-graduação. A base principal de dados utilizada foi o site do Conselho Federal de Odontologia. Conclui-se que a Odontologia Legal mostrou um promissor mercado de trabalho, com boas perspectivas de atuação tanto na docência como nas perícias judiciais em âmbito civil.
\end{abstract}

Descritores: Odontologia Legal. Ética Odontológica. Conhecimentos, Atitudes e Prática em Saúde. Mercado de Trabalho.

\section{INTRODUÇÃO}

A Odontologia Legal seria a disciplina que oferece à justiça os conhecimentos da Odontologia e suas diversas especialidades ${ }^{1}$. Dentre as diversas possibilidades de atuação, encontram-se a docência, bem como as perícias nos diferentes foros. Nesse contexto, encontramse as existentes em âmbito cível, nas quais o especialista é nomeado para conduzir o trabalho pericial em demandas que envolvem muitas vezes a responsabilidade profissional ou a valoração de danos ${ }^{2,3}$. 
A política de formação de recursos humanos para a Odontologia está levando a uma visível saturação do campo de trabalho privado, principalmente nos grandes centros, verificandose o excesso de profissionais dentistas ${ }^{4}$. Nesse cenário, a Odontologia Legal, apesar de ser área de conhecimento especifico, ligando a ciência odontológica com a ciência jurídica, na prática profissional, se correlaciona com todas as demais especialidades odontológicas ${ }^{5}$.

No âmbito do ensino de graduação existe uma orientação por mudanças propostas pela Associação Brasileira de Odontologia Legal (ABOL) junto a Associação Brasileira de Ensino Odontológico (ABENO) na disciplina de Odontologia Legal: na graduação ela seria dividida em duas partes com carga horária mínima de 60 horas cada, uma ministrada no início do curso e outra próxima ao final, contemplando uma maior abrangência de conteúdos e também práticas de campo voltado ao efetivo exercício de atividades de importância ética-legal na Odontologia $^{6}$.

Em relação à pós-graduação em nível de especialização, segundo o Conselho Federal de Odontologia (CFO), sejam ministrados em entidades representativas da classe ou instituições de ensino superior, são obrigatórias as inclusões das disciplinas de Ética e Legislação Odontológica, com o mínimo de 30 horas $^{2}$. Sendo que nos cursos de pós-graduação (nessas 30 horas previstas), além das discussões e reflexões relativas à legislação odontológica, são abordados ainda conteúdos relacionados à responsabilidade profissional e a importância do prontuário odontológico ${ }^{7}$.

Também de acordo com as Normas do $\mathrm{CFO}^{2}$, a perícia em foro civil é determinada como área de competência para atuação do especialista em Odontologia Legal. Nesse âmbito, o perito é um importante auxiliar na resolução de conflitos judiciais, tendo como tarefa trazer luz à Justiça nas questões acerca de conhecimentos de sua área profissional quando a resolução da divergência extrapolar os conhecimentos técnicos do $\mathrm{Juiz}^{8}$. Nesse contexto, verifica-se que o número de processos movidos contra os profissionais da saúde tem aumentado com o passar dos anos, sendo que figuram várias especialidades em processos dependendo das regiões do Brasil analisadas (cirurgia, prótese, ortodontia, implantodontia e outras), sendo mais prevalentes entre os estudos disponíveis a Implantodontia e a Ortodontia $9,10,11$ e 12.

O presente estudo tem como objetivo correlacionar dados disponíveis sobre inscritos nas especialidades odontológicas, cursos de especialização existentes e faculdades de Odontologia registradas no Brasil, destacando a perspectiva de atuação do especialista em Odontologia Legal em docência e âmbito civil.

\section{MATERIAIS E MÉTODOS}

Trata-se de uma pesquisa descritiva, quantitativa e bibliográfica, com levantamento percentual, numérico e geográfico. A base principal utilizada foi o site do $\mathrm{CFO}^{13}$. Foram compilados dados sobre o quantitativo numérico de especialistas em Odontologia Legal, Implantodontia e Ortodontia. Foi também executado um levantamento numérico dos cursos de graduação e pós-graduação. Todos dados foram separados pela localização, por estado e regiões brasileiras para análise da distribuição geográfica, cálculo percentual e comparação entre os especialistas de Odontologia Legal, possíveis atuantes em foro civil, versus especialistas Ortodontia e Implantodontia, escolhidas por serem atualmente, as especialidades com maior demanda em processos judiciais no Brasil ${ }^{10}$.

Por tratar-se de uma coleta de dados públicos e de livre acesso, não envolvendo seres humanos, o presente estudo não foi submetido à 
apreciação de um Comitê de Ética em Pesquisa.

\section{RESULTADOS}

Consultando os dados fornecidos pelo próprio CFO, e ilustrados na figura 1 , temos dez especialidades concentrando $95 \%$ dos especialistas: Ortodontia, Implantodontia, Endodontia, Prótese Dentária, Periodontia, Ortopedia
Funcional dos Maxilares, Dentística, Cirurgia e Traumatologia Buco Maxilo Facial, Radiologia e Saúde Coletiva e da Família. A Odontologia Legal, com total de 628 profissionais, figura os 5\% restantes, sendo superior em número apenas a Odontologia para Pacientes com Necessidades Especiais, Odontogeriatria e Prótese Bucomaxilofacial ${ }^{13}$.

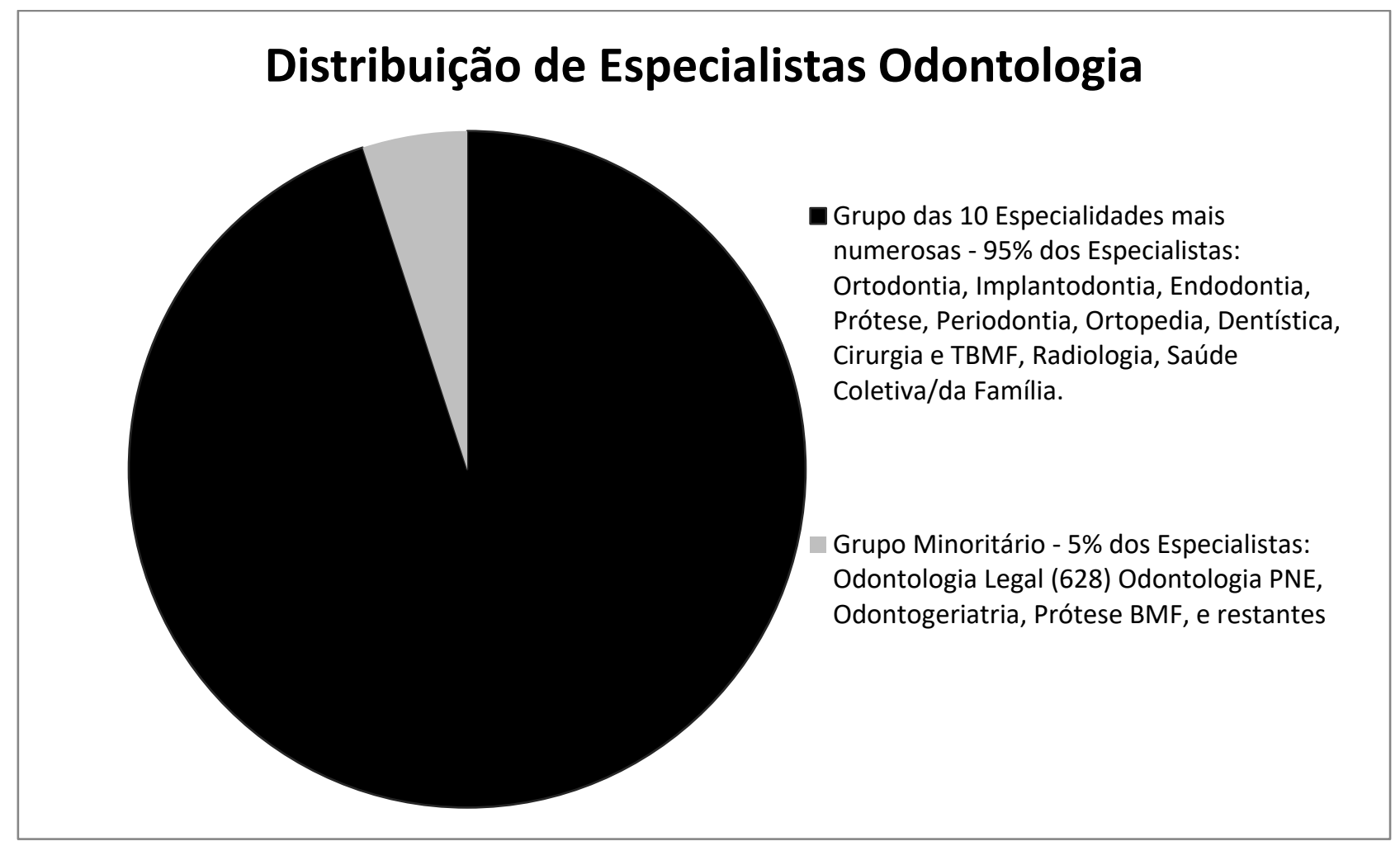

Figura 1: Distribuição de especialidades odontológicas.

$\mathrm{Na}$ tabela 1, é possível verificar a numérica e percentual de cirurgiões-dentistas disposição do número de cursos de registrados no CRO e as especialidades de especialização reconhecidos e/ou credenciados pelo CFO divididos por Estado do Brasil e na tabela 2 a divisão por região. Odontologia Legal, Ortodontia e Implantodontia no Brasil e por estado ${ }^{10}$. Em sequência no Quadro No quadro 1 se encontra a comparação 2 os mesmos dados, mas agrupados por regiões do Brasil. 
Perspectivas de atuação como docente e em foro civil para o especialista em Odontologia Legal

Tabela 1. Cursos de especialização reconhecidos e credenciados, e faculdades de Odontologia por estado brasileiro.

\begin{tabular}{|c|c|c|}
\hline Estado & Cursos de especialização credenciados e reconhecidos em andamento & Faculdades de Odontologia \\
\hline Acre & 0 & 1 \\
\hline Alagoas & 1 & 3 \\
\hline Amapá & 0 & 2 \\
\hline Amazonas & 2 & 7 \\
\hline Bahia & 2 & 11 \\
\hline Ceará & 7 & 4 \\
\hline Distrito Federal & 9 & 6 \\
\hline Espirito Santo & 2 & 4 \\
\hline Goiás & 7 & 5 \\
\hline Maranhão & 0 & 4 \\
\hline Mato Grosso & 6 & 5 \\
\hline Mato Grosso do Sul & 1 & 3 \\
\hline Minas Gerais & 83 & 25 \\
\hline Pará & 6 & 3 \\
\hline Paraíba & 1 & 5 \\
\hline Paraná & 52 & 15 \\
\hline Pernambuco & 6 & 7 \\
\hline Piauí & 2 & 4 \\
\hline Rio de Janeiro & 88 & 20 \\
\hline Rio Grande do Norte & 2 & 3 \\
\hline Rio Grande do Sul & 28 & 14 \\
\hline Rondônia & 2 & 3 \\
\hline Roraima & 2 & 1 \\
\hline Santa Catarina & 21 & 11 \\
\hline São Paulo & 90 & 47 \\
\hline Sergipe & 1 & 2 \\
\hline Tocantins & 1 & 5 \\
\hline Brasil & 422 & 210 \\
\hline
\end{tabular}

* Dados coletados no site do CFO em junho/2016 
Tabela 2. Cursos de especialização e faculdades de Odontologia por regiões do Brasil.

\begin{tabular}{l|c|c}
\multicolumn{1}{c|}{ Região } & Cursos de especialização credenciados e reconhecidos em andamento & Faculdades de Odontologia \\
\hline Sul & 101 & 40 \\
\hline Sudeste & 263 & 96 \\
\hline Centro-Oeste & 23 & 18 \\
\hline Nordeste & 22 & 43 \\
\hline Norte & 13 & 22 \\
\hline
\end{tabular}

* Dados coletados no site do CFO em junho/2016

Quadro 1. Comparação numérica e percentual de cirurgiões-dentistas registrados no CRO e as especialidades de Odontologia Legal, Ortodontia e Implantodontia no Brasil e por Estado.

\begin{tabular}{|c|c|c|c|c|c|c|c|c|}
\hline Estado & CDs & $\begin{array}{c}\text { CDs/ } \\
\text { Total Brasil }\end{array}$ & $\begin{array}{c}\text { Especialistas } \\
\text { OL }\end{array}$ & $\begin{array}{c}\text { Especialistas } \\
\text { OL/Estado }\end{array}$ & $\begin{array}{c}\text { Especialistas } \\
\text { Orto }\end{array}$ & $\begin{array}{l}\text { Especialistas } \\
\text { Orto/Estado }\end{array}$ & $\begin{array}{c}\text { Especialistas } \\
\text { Impl }\end{array}$ & $\begin{array}{l}\text { Especialistas } \\
\text { Impl/Estado }\end{array}$ \\
\hline Acre & 642 & $0,23 \%$ & 3 & $0,46 \%$ & 36 & $5,60 \%$ & 22 & $3,42 \%$ \\
\hline Alagoas & 2714 & $0,98 \%$ & 9 & $0,33 \%$ & 116 & $4,27 \%$ & 35 & $1,28 \%$ \\
\hline Amapá & 613 & $0,22 \%$ & 5 & $0,81 \%$ & 44 & $7,17 \%$ & 20 & $3,26 \%$ \\
\hline Amazonas & 3670 & $1,33 \%$ & 8 & $0,21 \%$ & 176 & $4,79 \%$ & 97 & $2,64 \%$ \\
\hline Bahia & 11076 & $4,04 \%$ & 15 & $0,13 \%$ & 570 & $5,14 \%$ & 253 & $2,28 \%$ \\
\hline Ceará & 6225 & $2,27 \%$ & 6 & $0,09 \%$ & 400 & $6,42 \%$ & 124 & $1,99 \%$ \\
\hline Distrito Federal & 6885 & $2,51 \%$ & 18 & $0,26 \%$ & 753 & $10,93 \%$ & 580 & $0,84 \%$ \\
\hline Espirito Santo & 5329 & $1,94 \%$ & 9 & $0,16 \%$ & 506 & $9,49 \%$ & 332 & $6,23 \%$ \\
\hline Goiás & 9674 & $3,52 \%$ & 19 & $0,19 \%$ & 947 & $9,78 \%$ & 668 & $6,90 \%$ \\
\hline Maranhão & 3590 & $1,30 \%$ & 2 & $0,05 \%$ & 168 & $4,67 \%$ & 80 & $2,22 \%$ \\
\hline Mato Grosso & 4228 & $1,54 \%$ & 17 & $0,40 \%$ & 385 & $9.10 \%$ & 267 & $6,31 \%$ \\
\hline Mato Grosso do Sul & 3783 & $1,37 \%$ & 6 & $0,15 \%$ & 311 & $8,22 \%$ & 180 & $4,75 \%$ \\
\hline Minas Gerais & 32857 & $11,98 \%$ & 85 & $0,25 \%$ & 2758 & $8,39 \%$ & 1467 & $4,46 \%$ \\
\hline Pará & 4806 & $1,75 \%$ & 5 & $0,10 \%$ & 341 & $7,09 \%$ & 163 & $3,39 \%$ \\
\hline Paraíba & 4031 & $1,47 \%$ & 6 & $0,14 \%$ & 128 & $3,17 \%$ & 55 & $1,36 \%$ \\
\hline
\end{tabular}


(continuação)

\begin{tabular}{|c|c|c|c|c|c|c|c|c|}
\hline Paraná & 17840 & $6,50 \%$ & 52 & $0,29 \%$ & 1923 & $10,77 \%$ & 1077 & $6,03 \%$ \\
\hline Pernambuco & 7557 & $2,75 \%$ & 20 & $0,26 \%$ & 273 & $3,61 \%$ & 123 & $1,62 \%$ \\
\hline Piauí & 2724 & $0,99 \%$ & 0 & $0,00 \%$ & 103 & $3,78 \%$ & 45 & $1,65 \%$ \\
\hline Rio de Janeiro & 29962 & $10,92 \%$ & 88 & $0,29 \%$ & 2610 & $8,71 \%$ & 1140 & $3,80 \%$ \\
\hline Rio Grande do Norte & 3481 & $1,28 \%$ & 11 & $0,31 \%$ & 181 & $5,19 \%$ & 54 & $1,55 \%$ \\
\hline Rio Grande do Sul & 17272 & $6,30 \%$ & 52 & $0,30 \%$ & 2339 & $13,54 \%$ & 1011 & $5,85 \%$ \\
\hline Rondônia & 2007 & $0,73 \%$ & 17 & $0,84 \%$ & 178 & $8,86 \%$ & 122 & $6,07 \%$ \\
\hline Roraima & 609 & $0,22 \%$ & 4 & $0,65 \%$ & 31 & $5,09 \%$ & 20 & $3,28 \%$ \\
\hline Santa Catarina & 11009 & $4,01 \%$ & 17 & $0,15 \%$ & 1472 & $13.37 \%$ & 904 & $8,21 \%$ \\
\hline São Paulo & 84107 & $30,67 \%$ & 137 & $0,16 \%$ & 5263 & $6,25 \%$ & 2855 & $3,39 \%$ \\
\hline Sergipe & 1842 & $0,67 \%$ & 8 & $0,43 \%$ & 143 & $7,76 \%$ & 38 & $2,06 \%$ \\
\hline Tocantins & 1919 & $0,69 \%$ & 9 & $0,46 \%$ & 141 & $7,34 \%$ & 70 & $6,34 \%$ \\
\hline Brasil & 274158 & $100 \%$ & 628 & $0,22 \%$ & 22296 & $8,13 \%$ & 11802 & $4,30 \%$ \\
\hline
\end{tabular}

CDs: cirurgiões-dentistas; OL: Odontologia Legal; Orto: Ortodontia; Impl: Implantodontia. * Dados coletados no site do CFO em maio/2016 **As especialidades Ortodontia e Ortodontia e Ortopedia Facial (nomenclatura antiga) foram somadas.

Quadro 2. Dados numéricos e percentuais de cirurgiões-dentistas por região nas especialidades de Odontologia Legal, Ortodontia e Implantodontia.

\begin{tabular}{|l|c|c|c|c|c|c|c|c|}
\hline \multicolumn{1}{|c|}{ REGİ̃O } & CDs & $\begin{array}{c}\text { Coeficiente } \\
\text { de CDs }\end{array}$ & $\begin{array}{c}\text { Especialistas } \\
\text { em OL }\end{array}$ & $\begin{array}{c}\text { Coeficiente de } \\
\text { especialistas em } \\
\text { OL }\end{array}$ & $\begin{array}{c}\text { Especialistas } \\
\text { em Orto }\end{array}$ & $\begin{array}{c}\text { Coeficiente de } \\
\text { especialistas em } \\
\text { Orto }\end{array}$ & $\begin{array}{c}\text { Especialistas } \\
\text { em Impl }\end{array}$ & $\begin{array}{c}\text { Coeficiente de } \\
\text { especialistas em } \\
\text { Impl. }\end{array}$ \\
\hline Sul & 46121 & $16,82 \%$ & 121 & $19,26 \%$ & 5734 & $25,71 \%$ & 2992 & $25,35 \%$ \\
\hline Sudeste & 152255 & $55,53 \%$ & 319 & $50,79 \%$ & 11137 & $49,95 \%$ & 5794 & $49,09 \%$ \\
\hline Centro-Oeste & 24570 & $8,96 \%$ & 60 & $9,55 \%$ & 2396 & $10,74 \%$ & 1695 & $14,36 \%$ \\
\hline Nordeste & 43240 & $15,77 \%$ & 76 & $12,10 \%$ & 2082 & $9,33 \%$ & 808 & $6,84 \%$ \\
\hline Norte & 14266 & $5,20 \%$ & 41 & $6,52 \%$ & 947 & $4,24 \%$ & 514 & $4,35 \%$ \\
\hline Total BRASIL & 274158 & $100 \%$ & 628 & $100 \%$ & 22296 & $100 \%$ & 11802 & $100 \%$ \\
\hline
\end{tabular}

CDs: cirurgiões-dentistas; OL: Odontologia Legal; Orto: Ortodontia; Impl: Implantodontia. * Dados coletados no site do CFO em maio/2016 


\section{DISCUSSÃO}

A inclusão obrigatória da Odontologia Legal no currículo dos cursos de Odontologia ocorreu a partir de 1932, o que propagou seu estudo entre os profissionais, contudo tanto estudantes como profissionais formados não dedicam o interesse devido nesta área especifica da Odontologia, somente atendando a sua importância diante do primeiro problema na esfera judicial ${ }^{1}$.

Ao graduar-se, o cirurgião-dentista adquire plena capacidade para atuar como perito, e habilitação para o mesmo, porém os simples conhecimentos da graduação são incipientes para o profissional desincumbir-se da delicada tarefa de levar a efeito uma perícia. Diante do atual aumento da demanda para os peritos com situações envolvendo o exercício profissional, avaliação de dano, lesões dento-faciais de acidentes, infortúnios do trabalho entre outras, diversos autores tem deixado consolidado a condição recomendável de formação especializada, que não é obtida somente com os ensinamentos dos cursos de graduação ${ }^{3,14,15 \text { e } 16 .}$

$O$ processo de formação acadêmica na Odontologia passou por transformações nas últimas três décadas, acompanhando orientações advindas dos serviços de saúde, como produto das reais necessidades da população. Adicional a este, as iniciativas Ministeriais e os programas de fomento criados para viabilizarem a interação acadêmica com os serviços de saúde direcionaram a um reordenamento dos caminhos do ensino odontológico no Brasil ${ }^{17}$.

Historicamente temos persistência de uma formação acadêmica voltada às atividades curativas, carente de discussões éticas, dependente do desenvolvimento técnicocientífico com tecnologia de ponta, com disciplinas cada vez mais subespecializadas e focadas mais na doença e suas sequelas do que no próprio paciente, com baixa capacitação e pouca utilização da epidemiologia, aspectos econômicos, sociais e ciências humanas ${ }^{18}$. A especialidade de Odontologia Legal também sofre influência dos reflexos desta situação.

Mesmo após a implantação das Diretrizes Curriculares Nacionais em Odontologia $(\mathrm{DCN})^{19}$, a consequente proposta do currículo integrado $^{20}$ e o Programa Nacional de Reorientação da Formação Profissional em Saúde (PRO-SAÚDE) ${ }^{21}$, os avanços positivos na alteração curricular foram poucos e distribuídos sem uniformidade nos cursos Odontologia $^{22}$. Dentro da perspectiva de superação deste panorama, a disciplina de Odontologia Legal seria fundamental para articulação desta mudança curricular, visto que trabalha a valorização da responsabilização ética e legal no exercício da Odontologia ${ }^{5}$, um dos requisitos fundamentais ao novo perfil de formação profissional.

No presente estudo verificou-se a existência de 210 Faculdades de Odontologia no Brasil, com maior concentração nas regiões Sul e Sudeste, com coincidente concentração de especialistas em Odontologia Legal nestas mesmas regiões, conforme demonstrado no quadro 2 e tabela 2. Analisando o campo de trabalho para docência nessas universidades, se cada uma empregasse ao menos um especialista em Odontologia Legal como docente, essa demanda já absorveria aproximadamente um terço dos especialistas em Odontologia Legal inscritos no CFO (628 profissionais).

Já em relação aos cursos de pós-graduação existentes (conforme consta no quadro 1), a soma de todos existentes mostra 422 cursos, sendo cada um com 30 horas obrigatórias de ética e legislação. Logo, haveria 12.660 horas/aula dessa disciplina a ser ministrada nos diferentes cursos. Caso fossem chamados para essa tarefa os especialistas em Odontologia Legal, com vocação, competência e interesse na 
docência, haveria 20 horas/aula para cada um inscrito ministrar (12.660 horas/aula por 628 inscritos na especialidade). Pela Resolução 63/2005 do CFO, é área de atuação dos especialistas em Odontologia Legal a Deontologia Odontológica e a orientação odontolegal para o exercício profissional ${ }^{2}$.

A docência na Odontologia Legal constitui uma oportunidade franca, dado o momento em que as discussões em torno da disciplina direcionam a um processo de reavaliação e expansão, com tendência a aumento de carga horária e maior valorização e exigência do professor como especialista, mestre ou doutor. A premissa é sair do monótono ensino de ética e legislação paralelo com Instituições que mantem docentes sem a qualificação específica, para uma carga horária expandida e uma disciplina de Odontologia Legal mais abrangente e dinâmica, com professores mais qualificados e orientados pela necessidade de formação de profissionais voltados ao atual contexto sócio-econômicocultural nacional.

Em relação ao campo de atuação junto as Instituições, somente $25 \%$ dos Ministérios Públicos (MPs) brasileiros (entre estaduais e federais), por exemplo, possuem em seus quadros o profissional cirurgião-dentista, sendo que desses, $7,2 \%$ utilizam estes profissionais para atividades de assistência técnica judicial junto aos membros da Instituição. Com estas constatações observa-se uma margem para novos postos de odontolegistas junto a essa instituição essencial a justiça, e que, analisada a legislação vigente no tocante ao assessoramento técnico, a especialidade odontológica que mais se enquadra nas demandas dos MPs é o profissional de Odontologia Legal ${ }^{23}$. No trabalho realizado, encontrou-se o estado do Piauí com coeficiente de especialistas em Odontologia Legal zero, ou seja, não existiriam profissionais com o conhecimento especializado para realização dessas atividades, caso fosse exigida a Especialidade para ingresso no concurso. A condição de baixa concentração de profissionais inscritos na região norte e nordeste já foi verificada por Paranhos et al (2009a) ${ }^{24}$, e atualmente temos menos de 10 especialistas em Odontologia Legal registrados nos estados do Acre, Alagoas, Amapá, Amazonas, Ceará, Maranhão, Pará, Paraíba, Roraima e Sergipe; fora da região Norte/Nordeste as únicas exceções são Espirito Santo e Mato Grosso do $\mathrm{Sul}^{13}$.

Temos um número significativo de experiência processual nas especialidades de Ortodontia e Implantodontia relacionado a vários fatores como: alto custo de tratamento, tempo de tratamento mais longo e expectativa estética $^{10}$. Embora as mesmas estejam na relação de especialidades odontológicas do SUS, ainda é baixa a oferta no sistema público, o que condiciona a alternativa de tratamento particular a quem necessita e tem condições de custeá-lo.

Para o especialista em Odontologia Legal a demanda mais alta nessas duas especialidades indica, além da valoração de danos corporais envolvendo a Odontologia e advindos do erro profissional, a necessidade de conhecimento mais especifico das mesmas. Este fato chama atenção e pode servir como estímulo para ortodontistas e implantodontistas investirem na especialização na área forense, podendo atuar de forma mais consistente em casos que envolvam as duas áreas.

Em uma análise percentual comparando a diferença entre o coeficiente de especialistas de Odontologia Legal e os especialistas em Ortodontia somados a Implantodontia, observase maior diferença entre os coeficientes nos estados de Santa Catarina/SC 21,43\%, Rio Grande do Sul/RS 19,09\% e Paraná/PR 16,51\%, o que indica como sendo estes os melhores para atuar nas perícias em foro civil, o estado com 
menor diferença percentual foi o da Paraíba/PB 4,39\%. Esses dados encontram respaldo no trabalho de Paranhos et al. (2009b) ${ }^{25}$, que mostra a Especialidade de Odontologia Legal com um inscrito naquele ano no Estado do RS e dez em SC.

A auditoria odontológica no setor público, mais especificamente no Sistema Único de Saúde (SUS) está em crescimento, a atuação do auditor odontológico é abrangente no gerenciamento do sistema, consistindo no controle, na avaliação, orientação e na supervisão, bem como na garantia de acesso aos serviços e participação social. $\mathrm{O}$ auditor deve ter como objetivo manter o equilíbrio do sistema, possibilitando o direito à saúde para todos, garantir a qualidade dos serviços oferecidos e prestados e fazer cumprir os preceitos legais. A auditoria odontológica no sistema público carece de mais estudos, mas o sistema de auditoria é um instrumento administrativo confiável e essencial para os gestores no desenvolvimento das ações de saúde, atualmente com maior alusão a um enfoque educativo e não mais policialesco a resolubilidade dos problemas ${ }^{26}$.

A conjuntura do atual do SUS com déficit de atendimento as necessidades da população com causas relacionadas à crônica insuficiência de recursos e problemas de gestão promoveu franca expansão no setor de auditoria odontológica do setor privado. Aliada a crise no mercado odontológico provocada pelo excesso de profissionais, muitos cirurgiões-dentistas passaram a fazer parceria com as Operadoras de Planos de Saúde (OPS), na expectativa de manter e aumentar clientela, o que tem promovido uma reorganização acelerada e irreversível do setor em que a relação entre paciente e cirurgião-dentista é intermediada pela OPS, com a figura do auditor com elemento qualificador dos serviços ${ }^{27}$. Pelas normativas do CFO, compete ao especialista em Odontologia
Legal, também facultado ao clínico geral habilitado, a perícia em âmbito administrativo, como as perícias ocupacionais e as auditorias, sendo realizada por solicitação de dirigentes ou autoridades de setores ligados aos recursos humanos no âmbito público ou privado ${ }^{2}$.

Outra possibilidade de atuação para o especialista em Odontologia Legal é junto às equipes de vigilância sanitária, orientando ações: normatização e vigilância de serviços odontológicos, controle e monitoramento da qualidade da água de abastecimento público e sua fluoração, vigilância de produtos contendo flúor, controle de resíduos tóxicos e contaminados produzidos por estabelecimentos de saúde e vigilância epidemiológica das principais doenças. As práticas de vigilância foram tradicionalmente estruturadas e orientadas pelas demandas espontânea e pontual, tendo um forte componente autoritário e fiscalizador: fazse vigilância "sobre" os profissionais e não "com" a participação ativa deles e, como consequência, os programas perdem a efetividade. Por este motivo é imprescindível à estruturação de um projeto de atuação cuja metodologia coloque a educação em saúde como ferramenta na mudança de comportamentos profissionais, melhorando a informação e motivando a compreensão da necessidade de um novo comportamento perante velhas práticas.

Para que resultados de impacto sejam obtidos nas ações propostas, são necessárias também à articulação e a integração de diversos setores, e principalmente, a participação dos cidadãos, isso requer que o especialista em Odontologia Legal na condição de responsável pelas ações de vigilância buscando a legitimidade social ${ }^{28}$. Nesse aspecto, a formação em Odontologia Legal prevê como conteúdos na formação tópicos sobre perícia, avaliação e planejamento em infortunística, permitindo uma prática mais consistente nesse campo de 
atuação.

Embora atualmente hajam sítios eletrônicos para consulta dos Programas de PósGraduação lato sensu (pelo site do CFO) onde se observam vários cursos de especialização em Odontologia Legal disponíveis para análise, não se observa a mesma situação ao pesquisar sobre a modalidade stricto sensu (mestrados e doutorados) no site da Plataforma Sucupira relacionados à Odontologia Legal no Brasil, ou seja, os programas existentes são vinculados a programas maiores. Digno de registro que para verificação de programas stricto sensu, sequer existe a possibilidade de pesquisar a Odontologia Legal como área básica, tampouco como Odontologia Forense. Nessa esteira, destacam-se os dois programas pioneiros na área de concentração em Odontologia Legal, ambos criados ao final da década de noventa e ainda em funcionamento hoje no Brasil: na Faculdade de Odontologia de Piracicaba da Universidade Estadual de Campinas (FOP/Unicamp) criado pelo ilustre Prof. Dr. Eduardo Daruge (in memorian), hoje vinculado ao programa de Pós Graduação em Biologia Buco-Dental, assim como na Universidade de São Paulo criado pelo eminente Prof. Dr. Moacyr da Silva, nos dias de hoje relacionado ao Programa de Ciências Odontológicas. Com isso a perspectiva para a carreira docente e na área de pesquisa em ciências forenses tem um amplo leque de possibilidades (ao considerar-se o contato com outras disciplinas), bem como as atividades cíveis, como perito ou assistente técnico, sendo excelentes oportunidades tanto no âmbito público como na iniciativa privada ${ }^{17}$.

Por fim, vislumbram-se perspectivas positivas para a especialidade de Odontologia Legal, todas as opções analisadas se mostram em fraca expansão de trabalho, sendo uma especialidade com um potencial mercadológico a ser explorado, podendo gerar excelentes oportunidades de trabalho tanto no público como no privado, a julgar pelos relevantes serviços que presta a justiça e à sociedade, produzindo implicações diretas na vida profissional do cirurgião-dentista e nas suas relações sociais e humanas.

\section{CONCLUSÔES}

A análise dos resultados permite concluir que a Odontologia Legal mostrou um mercado de trabalho promissor e com boas perspectivas de atuação tanto na docência como nas perícias judiciais em âmbito civil. Mesmo com os dados e informações apresentados, uma conjuntura de decisões na área da educação como um todo, e do setor público da esfera da saúde e judicial poderá mudar positivamente a demanda de especialistas e favorecer a necessidade de mais odontolegistas.

\section{ABSTRACT \\ Perspectives in teaching and civil liability expertise for forensic dentist}

The forensic dentistry relates to all other dental specialties, making the connection between dentistry and law. Among the various possibilities of action, are teaching, as well as skills in various forums, and in this context, existing in civil context in which the expert is appointed to conduct the forensic work demands often involving professional responsibility. This study aims to correlate available data on enrolled in dental specialties, existing specialization courses, and dental schools registered in Brazil, highlighting the expert performance perspective in Forensic Dentistry in teaching and civil forensic practice. This is a descriptive observational analysis that was prepared a coefficient of experts in specialties with more demands in legal proceedings in Brazil (orthodontics and implantology) in each Brazilian state from the data available on the website of the Federal Council of Dentistry (CFO) and collected and compiled data on experts in Forensic Dentistry, specialization 
courses and existing dental schools in the country. It is concluded that the forensic dentistry showed a potential labor market, expanding, and with good prospects for action both in academic as in judicial expertise in civil matters.

Descriptors: Forensic Dentistry. Ethics, Dental. Health Knowledge, Attitudes, Practice. Job Market.

\section{REFERÊNCIAS}

1. Vanrell JP. Odontologia Legal e Antropologia Forense. 2nd ed. Rio de Janeiro: Guanabara Koogan; 2009.

2. Brasil. Conselho Regional de Odontologia. Resolução CFO 63/2005 C2016 Diério Oficial da República Federativa do Brasil, Brasilia (DF), 2005 abr 19. Seção 1, p. 104. Disponivel em: http://cfo.org.br/.

3. Silva Md. Compêndio de Odontologia Legal. $1^{\circ}$ ed. Rio de Janeiro: Guanabara Koogan; 1997.

4. Pereira AC, Mialhe FL, Pereira SM, Meneghim MdC. O mercado de trabalho odontológico em saúde coletiva: possibilidades e discussões. Arq Odontol. 2010;46(4):232-9.

5. Lino-Júnior HL, Gabriel M, Daruge-Júnior E, Silva RHAd. Ensino de Odontologia Legal no Brasil: um covite à reflexão. Rev ABENO. 2015;15(2):38-46.

6. ABOL. ABENO. 2010 Disponivel em: http://www.abeno.org/noticias/noticias020. php.

7. Zaitter WM. Consequências éticas de comentários sobre trabalhos odontológicos realizados por outro colega de profissão. 2000. Dissertação (Mestrado em Odontologia Legal) - Faculdade de Odontologia, Universidade de São Paulo; 2000.

8. Petille R, Silva RHAd. Perícia Cível em Odontologia Legal: Credeciamento e honorários do Perito Judicial. RBOL. 2015; 2(2):63-81.

9. Rosa FM, Fernandes MM, Júnior ED, Paranhos LR. Danos materiais e morais em processos envolvendo cirurgiões-dentistas no estado de São Paulo. RFO-UPF 2012; 17(1):26-30.

10. Lima RBWe, Moreira VG, Cardoso AMR, Nunes FMR, Rabello PM, Santiago BM. Levantamento das Jurisprudências de Processos de Responsabilidade Civil Contra Cirurgiões-Dentistas nos Tribunais de Justiça Brasileiros. Rev Bras Ciênc Saúde. 2012;16(1):49-58.

11. Terada ASSD, De Araujo LG, Flores RP, Da Silva RHA. Responsabilidad Civil del Cirujano-Dentista: Análisis de las Demandas Presentadas en el Municipio de Ribeirão Preto - São Paulo, Brasil. Int J Odontosmatol. 2014;8(3):365-9.

12. Castro ACCd, Franco A, Silva RF, Portilho CDM, Oliveira HCMd. Prevalência e conteúdo das jurisprudências fundamentadas em erro odontológico nos Tribunais de Justiça do Centro-Oeste brasileiro. RBOL. 2015;2(1):46-52.

13. Brasil. Conselho Federal de Odontologia. CFO. Disponivel em: http://cfo.org.br/ imprensa/dados-estatisticos/.

14. Leite VdG. Odontologia Legal Salvador: Nova Era; 1962

15. Arbenz GO. Medicina Legal e Antropologia Forense Rio de Janeiro/São Paulo: Atheneu; 1988.

16. Rovida TAS, Garbin CAS. Noções de Odontologia Legal e Bioética. $1^{\mathrm{a}}$ ed. São Paulo: Artes Médicas; 2013.

17. Silva RHAd. Orientação Profissional para o cirurgião-dentista: ética e legislação. $1^{\mathrm{a}}$ ed. São Paulo: Santos; 2010.

18. Paula L, Bezera AC. A estrutura curricular dos cursos de Odontologia no Brasil. Rev ABENO. 2003;3:13-6.

19. Brasil. Ministério da Educação. Resolução CNE/CES 3/2002. Disponível em: http://portal.mec.gov.br/cne/arquivos/pdf/C ES032002.

20. Toassi RFC, Stobäus DC, Mosquera JJM, Moysés JS. Cúrriculo integrado no ensino de Odontologia. Interface Comun Educ Saúde. 2012;16(41):529-42.

21. Brasil. PRÓ-SAÚDE. [Online].; 2014 [Acesso em 19 abr. 2016]. Disponível em 
http://www.prosaude.org/.

22. Silva MAMd, Amaral HL, Senna MIB, Ferreira EF. O Pró-Saúde e o incentivo à inclusão de espaços diferenciados de aprendizagem nos cursos de odontologia no Brasil. Interface Comun Educ Saúde. 2012; 16(42):707-17.

23. Fernandes MM, Bragança DPPd, Oliveira OFD, Franscesquini Júnior L, Daruge Júnior E. O mercado de trabalho para a odontologia nos Ministérios Públicos. Rev Odontol Univ Cid São Paulo. 2009; 17(33):13-6.

24. Paranhos LR, Ricci D, Almeida Filho RPd, Scanavini MA. Análise do mercado de trabalho odontológico na região norte do Brasil. Rev Odontol Univ Cid São Paulo. 2009; 17(34):27-36.

25. Paranhos LR, Ricci ID, Scanavini MA, Bérzin F, Ramos AL. Análise do mercado de trabalho na odontológico na região Sul do Brasil. RFO UPF. 2009;14(1):7-13.
26. Ayach C, Moimaz SAS, Garbin CAS. Auditoria no Sistema Único de Saúde: o papel do auditor no serviço odontológico. Saúde Soc. 2013;22(1):237-48.

27. Vieira SLG, Miranda GE, Bouchardet FCH, Santos LE. A Auditoria Odontológica nos Serviços de Saúde Suplementar. SALUSVITA. 2014;33(3):331-43.

28. Aerts D, Abegg C, Kátia C. O papel do cirurgião-dentista no Sistema Único de Saúde. Ciênc Saúde Coletiva. 2004;9(1):131-8.

Correspondência para:

Fábio Elpídio Silva

e-mail: fabio.elpidio@yahoo.com.br

Av. Tancredo Neves, 5057 Casa 566

Conjunto Terra Nova

85867-000 Foz do Iguaçu, PR 